\title{
How Does Energy Intake Influence the Levels of Certain Steroids?
}

\author{
Beáta Rácz, Michaela Dušková, Hana Jandíková, Martin Hill, \\ Karel Vondra, Luboslav Stárka \\ Institute of Endocrinology, Prague, Czech Republic
}

Received September 10, 2015; Accepted November 16, 2015.

Key words: Steroid hormones - Melatonin - Food intake - Glucose

Abstract: The influence of steroid hormones on food intake is well described. However, there are only a few studies on the effect of food intake on steroid levels. The study involved eight non-smoker women (average age 29.48 \pm 2.99 years; average BMI $21.3 \pm 1.3 \mathrm{~kg} / \mathrm{m}^{2}$ ); they did not use any kind of medication affecting steroidogenesis. We analysed the influence of four various stimuli on the levels of steroid hormones and melatonin. During their follicular phase of menstrual cycle, each woman had an oral glucose tolerance test (OGTT), intravenous glucose tolerance test (IVGTT), a standard breakfast and psyllium (a non-caloric fibre). Cortisol declined during each test, which is a physiological decline in the morning hours. In all tests (except of the application of the non-caloric fibre, psyllium), however, this decline was modified. After the standard breakfast there was an increase in cortisol at $40^{\text {th }}$ minute. The OGTT and IVGTT tests led to a plateau in cortisol levels. Testosterone levels and those of other steroid hormones showed no relationships to tested stimulations. Oral and intravenous glucose have influenced physiological decline of melatonin levels. During the IVGTT test, melatonin levels started to increase at $20^{\text {th }}$ minute, reaching a maximum at $40^{\text {th }}$ minute. The OGTT test led to a delayed increase in melatonin levels, compared to IVGTT. Despite the fact that we performed the tests in the morning hours, when steroid hormone levels physiologically start to change due to their diurnal rhythm, we still found that food intake influences some of the hormone levels.

This study was supported by grant no. NT 12340 of the Internal Grant Agency of the Ministry of Health, Czech Republic.

Mailing Address: Michaela Dušková, MD., PhD., Institute of Endocrinology, Národní 8, 11694 Prague 1, Czech Republic; Phone: +420 224905 412;

e-mail: mduskova@endo.cz 


\section{Introduction}

Steroid hormones are hormones with lipophilic character synthesized from cholesterol in the gonads and adrenal glands, as well as locally in other tissues such as the brain (neurosteroids) and the placenta. In the plasma they are mainly bound to plasma proteins (albumin, or specific globulins such as corticosteroidbinding-globulin (CBG) or sex-hormone-binding globulin (SHBG)), and only a minor proportion (1-10\%) of hormones are found in free form. In target tissues they can act through two mechanisms: genomically through intracellular receptors, with function taking on the order of hours to days but also having lasting influence; and non-genomically, with rapid onset of function on the order of minutes or even seconds. This latter mechanism is typical for the activity of neuroactive steroids on nerve synapses, or the interaction of steroids with the GABA-A receptor.

Even though the daily profiles of the main sex hormones are well known, small oscillations in their levels that may be connected to food intake have yet to be systematically studied. Glucocorticoids have many various functions in organisms, and they influence the maintenance of the homeostasis. With rhythmic changes of the hormone levels, the hypothalamic-pituitary-adrenal (HPA) axis ensures tissue and organ-specific reactions of the organism to endogenous and exogenous stimuli (Lightman et al., 2008).

According to a study by Stárka et al. (2015), levels of DHEA and of its conjugated form androstenediol and 7a-hydroxy - DHEA decline one to two hours after lunch and dinner. Another recent study has described significant changes of estradiol and SHBG after food intake (Rácz et al., 2015). The influence of steroid hormones on the food intake is well known. In contrast, however, there are only a few published reports on how the food intake influences levels of steroid hormones.

Melatonin is a hormone that is associated with controlling of the circadian rhythm. It is mainly produced in the pineal gland during the night. The gastrointestinal tract seems to be the main source of melatonin during the daylight hours and also it is the main source of extrapineal melatonin. During the day, the gastrointestinal tract produces 400 times more melatonin than the pineal gland. This indicates the importance of melatonin in the pathophysiology of digestion.

The aim of our study was to analyse the influence of food intake on steroid hormone and melatonin levels. As stimuli we selected a standard breakfast, oral and intravenous glucose, and psyllium (as a model of mechanical effects of the food on the gastrointestinal tract).

\section{Methods}

The study participated eight women with average age of $29.48 \pm 2.99$ years and BMI of $21.3 \pm 1.3 \mathrm{~kg} / \mathrm{m}^{2}$. All of the women were pre-menopausal, they were non-smokers, healthy, and they were not using any medication or hormonal contraceptive. Blood samples were collected during the follicular phase (days 1-7 of the menstrual cycle). Five days before they had undergoing the tests, all 
of the women followed a standard protocol that did not vary much significantly from their normal daily routine ( 8 hours of sleep, food intake according to a standardized menu). Before the tests they were informed about the study protocol and they signed an informed consent form. The study was approved by the ethical commission of the Institute of Endocrinology in Prague.

Each woman passed the four different tests during four consecutive menstrual cycles:

1) OGTT - an oral glucose tolerance test - $75 \mathrm{~g}$ of glucose (Glukopur brand) in $250 \mathrm{ml}$ of unsweetened tee perorally.

2) IVGTT - an intravenous glucose tolerance test - a bolus of $0.33 \mathrm{~g}$ of glucose per $\mathrm{kg}$ of weight in $20 \%$ intravenous solution, administrated to a peripheral vein.

3) A standard breakfast - two slices of bread, $50 \mathrm{~g}$ of breast-meat chicken slices, 1 slice of fresh cheese (total caloric content of the breakfast was $515 \mathrm{kcal}$, total protein content: $20.58 \mathrm{~g}$, total carbohydrates: $47.75 \mathrm{~g}$, total fat: $24.9 \mathrm{~g}$ ).

4) Psyllium - a non-caloric fibre, which was meant to simulate mechanical stimulation of the gastrointestinal tract through distension. The women drank $4 \mathrm{~g}$ of psyllium in $250 \mathrm{ml}$ water.

An intravenous cannula was inserted into the cubital vein ten minutes before the first blood sampling. Sampling was performed for 120 minutes, with the following schedule:

- the first sampling was performed at 7:30 a.m. after overnight fasting

- subsequent samplings were performed at $20,40,60,90$, and 120 minutes.

\section{Analytical methods}

Each sample was collected into a plastic tube containing $100 \mu \mathrm{l}$ of $5 \%$ EDTA. Plasma was obtained after centrifugation for $5 \mathrm{~min}$ at $2000 \mathrm{rpm}$ at $4{ }^{\circ} \mathrm{C}$, then separated and frozen within half an hour of being drawn from the subject, and stored at $-20{ }^{\circ} \mathrm{C}$ until analysed.

C-peptide was measured in serum using ECLIA (electrochemiluminiscence immunoassay, Modular E 170 analyser, Roche). The measuring range of the kit (defined by the lower detection limit and the maximum of the master curve) was $0.003-13.3 \mathrm{nmol} / \mathrm{l}$ or $0.01-40.0 \mathrm{ng} / \mathrm{ml}$ for plasma. Intra- and inter-assay coefficients of variation were $1.5 \%$ and $2.3 \%$, respectively.

Blood glucose was measured using the enzymatic reference method with hexokinase (Cobas Integra 400 plus analyser, Roche). The measuring range of the kit was $0.12-40 \mathrm{mmol} / \mathrm{l}(2.16-720 \mathrm{mg} / \mathrm{dl})$. Intra-set and inter-set reproducibility were $1.7 \%$ and $2.6 \%$, respectively. Cortisol was measured using an RIA kit (Immunotech, France). Melatonin was measured using an RIA kit (Labor Diagnostika Nord $\mathrm{GmbH}$ and Co. KG, Germany). Sensitivity for melatonin was $2 \mathrm{pg} / \mathrm{ml}$, intra-assay and inter-assay coefficients of variation were $9.8-12.1 \%$ and $9.6-12.3 \%$, respectively. 
Steroid hormones measured by a GCIMS method

The levels of 37 unconjugated steroids and their polar conjugates were measured in cubital vein blood using a GC/MS method (Hill et al., 2010). In brief, free steroids were extracted from plasma by diethyl-ether; steroid conjugates were hydrolysed and extracted. The resulting residues were derivatized by methoxyamine hydrochloride and analysed by GC/MS as follows.

Steroids were purchased from Steraloids (Newport, RI, USA), Sylon B from Supelco (Bellefonte, PA, USA), methoxylamine hydrochloride from Sigma (St. Louis, MO, USA) and solvents from Merck (Darmstadt, Germany).

\section{Instruments}

Measurements of steroid levels were done on a GCMS-QP2010 Plus system by Shimadzu (Kyoto, Japan) consisting of a gas chromatograph equipped with automatic flow control, an AOC-20s autosampler, and a single quadrupole detector with an adjustable electron voltage of 10-195 V.A capillary column with a medium polarity RESTEK Rxi phase (diameter $0.25 \mathrm{~mm}$, length $15 \mathrm{~m}$, film thickness $0.1 \mu \mathrm{m}$ ) was used for analyses. Electron impact ionization with electron voltage fixed at $70 \mathrm{~V}$ and emission current set to $160 \mu \mathrm{A}$ was used. The temperatures of the injection port, ion source and interface were maintained at $220^{\circ} \mathrm{C}, 300{ }^{\circ} \mathrm{C}$, and $310^{\circ} \mathrm{C}$, respectively. Analyses were carried out in the splitless mode with a constant linear velocity of the carrier gas $(\mathrm{He})$, which was maintained at $60 \mathrm{~cm} / \mathrm{s}$. The septum purge flow was set at $3 \mathrm{ml} / \mathrm{min}$. The samples were injected using the high pressure mode $(200 \mathrm{kPa})$, which was maintained for $1 \mathrm{~min}$. The detector voltage was set to $1.4 \mathrm{kV}$.

\section{Statistical data analysis}

The changes of steroid levels and melatonin were evaluated using a repeated measures ANOVA model consisting of a Subject factor, explaining differences between subjects, and a Stage factor. Due to the non-Gaussian data distribution and non-constant variance, the original data were transformed by a power transformation to attain a symmetric distribution of the data and residuals as well as homoscedasticity (Meloun et al., 2000). The homogeneity of the transformed data was checked by residual analysis as described elsewhere (Meloun et al., $2002,2004)$. Then, the significance of the values was evaluated by least significant differences multiple comparisons.

\section{Results}

In order to better elucidate various findings on the influence of food intake on hormone levels, we studied the influence of several stimuli on the course of hormone levels. As stimuli we chose a standard breakfast, oral glucose, intravenous glucose and psyllium (chosen to follow mechanical effects of food on the gastrointestinal tract). The timeline of samplings was focused on monitoring and 


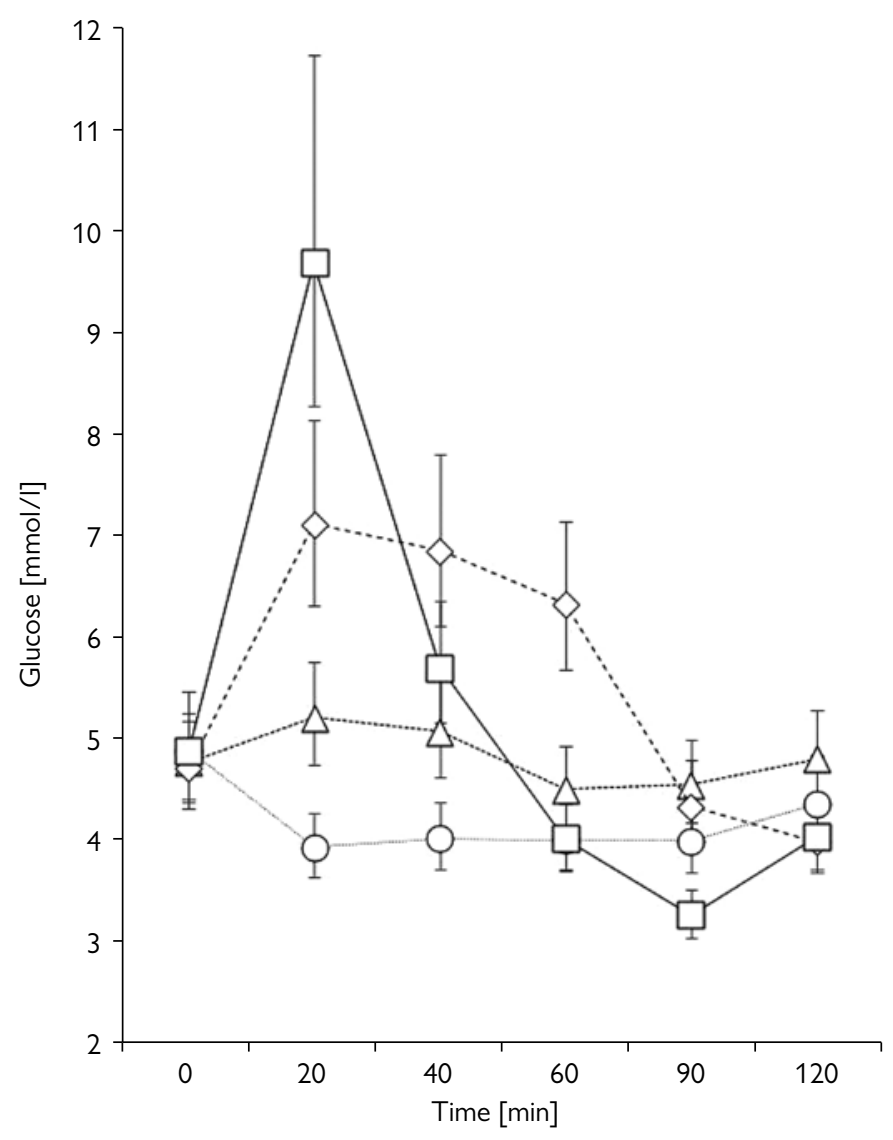

Figure 1 - Glycemia levels after individual stimuli.

$\Delta$ - standard breakfast; $\square-I V G T T ; \diamond-O G T T ; \circ-$ psyllium

analysing of acute and small changes of hormone levels after each stimulus. As we expected, the glycemia and C-peptide levels reflected normal values of a healthy population (Figures 1 and 2).

\section{Melatonin}

After all stimuli there was a decrease in melatonin levels at the beginning of the test after the first sampling. During IVGTT there was an increase in melatonin levels 20 minutes after giving glucose, and this increase lasted up to 60 minutes. A similar increase occurred after oral glucose, though the increase was later than in case of intravenous glucose (Figure 3).

\section{Cortisol}

There was a slowing of the physiological decline in cortisol levels after each of the stimuli, excepting psyllium. This slowing was most pronounced after intravenous 


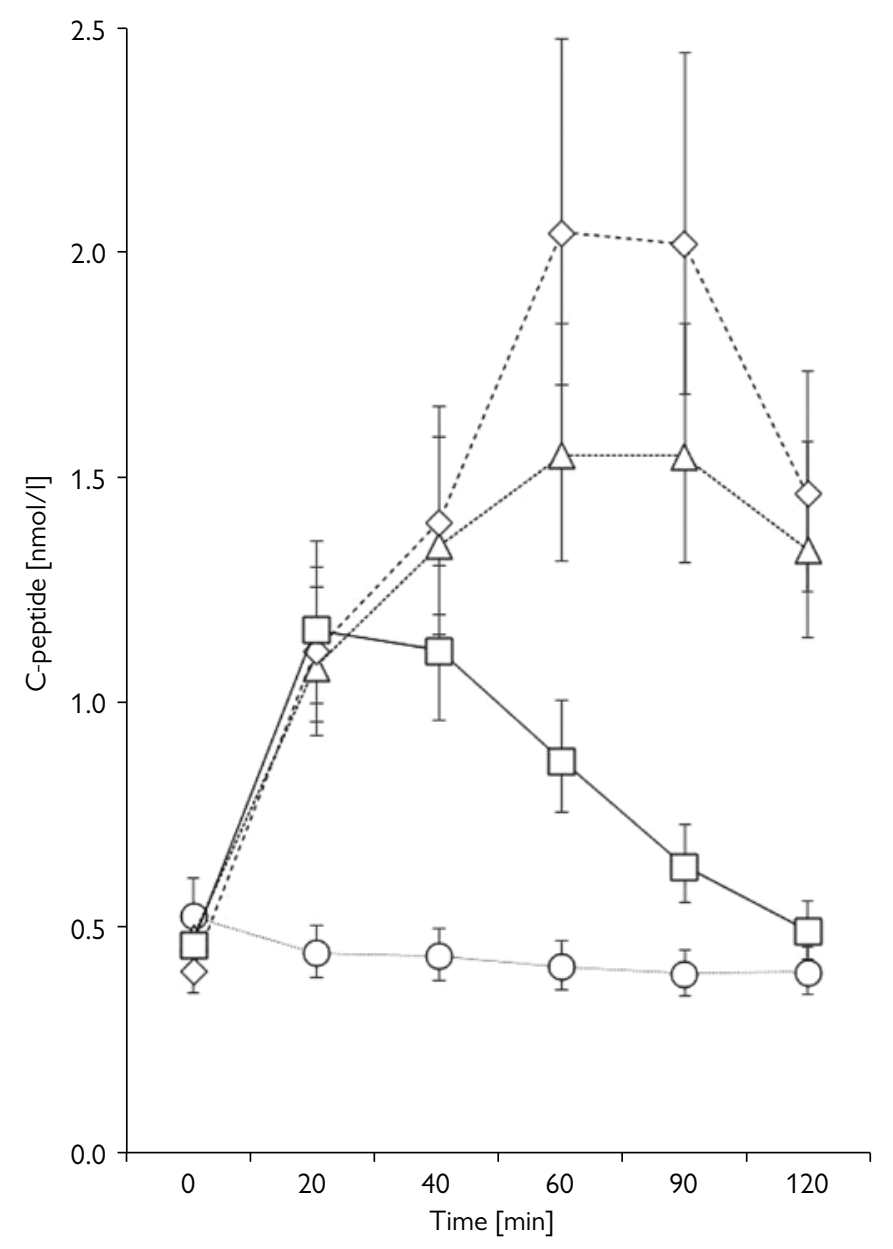

Figure 2 - C-peptide levels after individual stimuli.

$\Delta$ - standard breakfast; $\square-$ IVGTT; $\diamond-O G T T ; \circ-$ psyllium

glucose, lasting even 60 minutes. After oral glucose and intravenous glucose there was a plateau in cortisol levels, but after breakfast there was an increase in cortisol at $40^{\text {th }}$ minute (Figure 4 ).

\section{DHEA}

After the initial decline there was an increase in DHEA after all stimuli. This increase was most pronounced after intravenous glucose, but this increase was delayed compared to the other stimuli (Figure 5).

\section{Testosterone}

The course of testosterone levels did not have any significant relationship to any of the individual stimuli (Figure 6). 


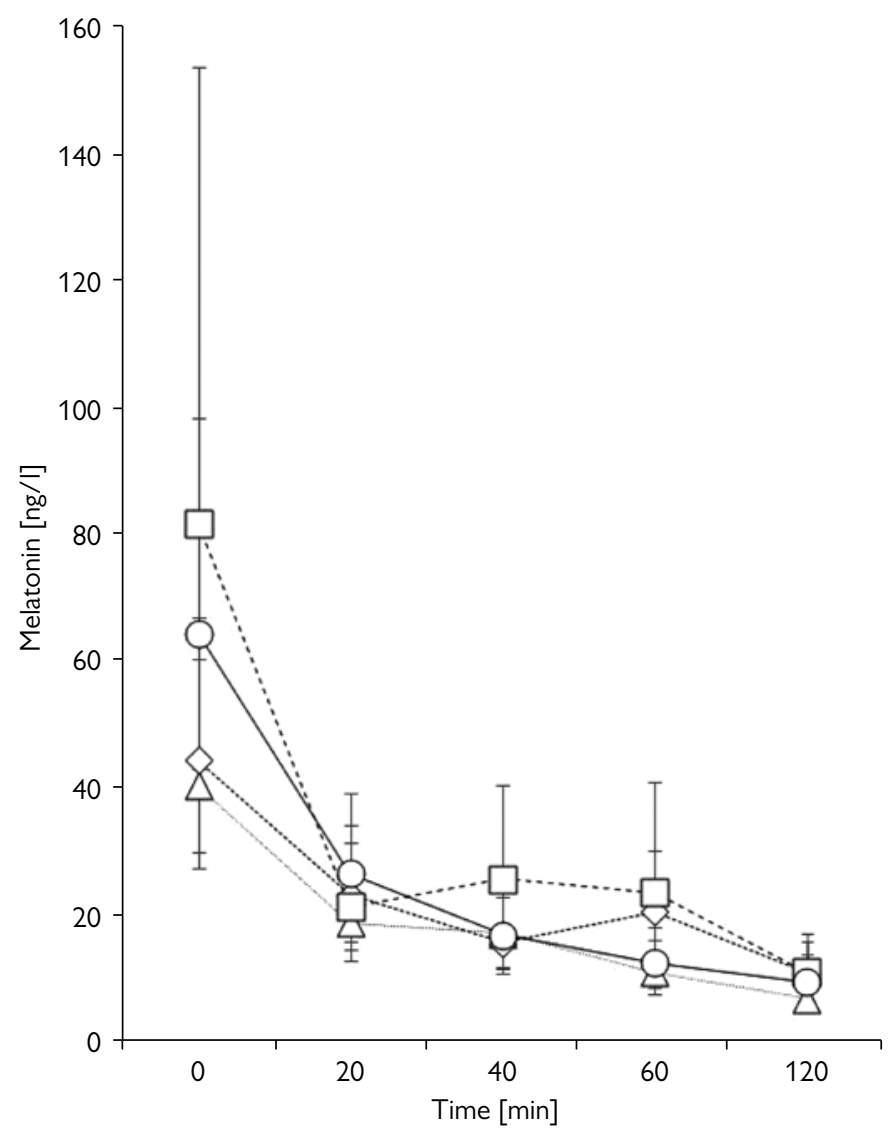

Figure 3 - Melatonin levels after individual stimuli.

$\Delta$ - standard breakfast; $\square$ - IVGTT; $\diamond$ - OGTT; ○ - psyllium

Similarly, non-conjugated and conjugated steroids also showed no relationships to individual stimuli, and we were unable to demonstrate a relationship between melatonin and the steroids studied.

\section{Discussion}

Recently, a number of studies have resulted in findings, about how dietary factors, such as caffeine (Sherman et al., 2011) and alcohol (Spanagel et al., 2005), can lead to changes of the circadian rhythm. It is assumed, that these changes are intermediated by melatonin (Peuhkuri et al., 2012). It is known, that starvation can lead to change of melatonin levels. In one study, restriction of energy intake for 2 days led to a decrease of plasmatic melatonin levels by $20 \%$, while application of glucose during starvation led to a return of melatonin levels to the normal (Röjdmark and Wetterberg, 1989). In our study, we found a decrease in melatonin 


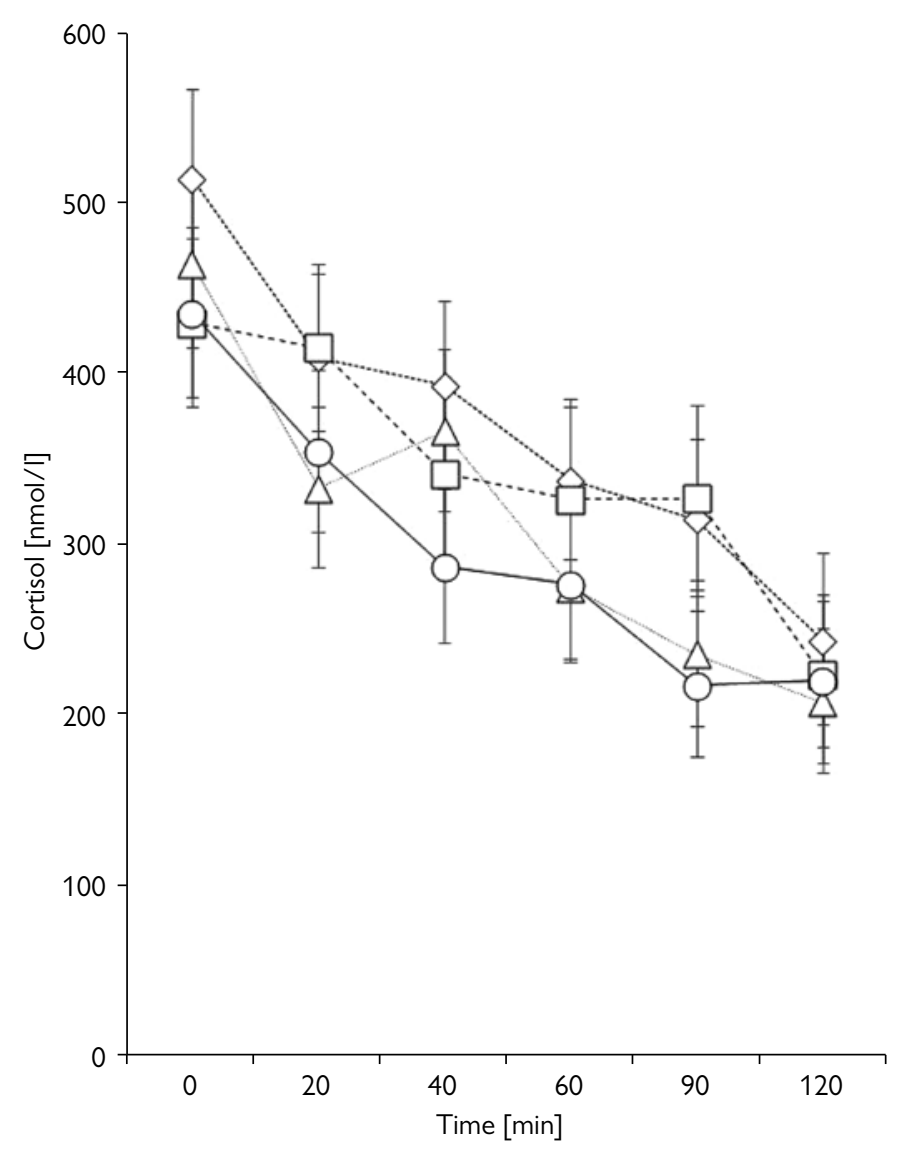

Figure 4 - Cortisol levels after individual stimuli.

$\Delta$ - standard breakfast; $\square-$ IVGTT; $\diamond-O G T T ; \circ-$ psyllium

levels after the first blood samples were drawn, which reflects the physiological behaviour of the melatonin. Forty minutes after the intravenous application of the glucose there was an increase in melatonin, which lasted up to the $60^{\text {th }}$ minute. Similarly, after giving of oral glucose there was an increase in melatonin levels, though delayed compared to its intravenous application. The reason is likely to the later onset of the hyperglycemia. In light of the fact, that neither the standard breakfast nor the non-caloric fibre led to a significant increase of the glycemia, it was either an increase of the melatonin levels observed.

It is well known the influence of corticoids on glucose metabolism and on increase of the glycemia (Lecocq et al., 1964). Some studies have described higher levels of circulating cortisol after each food intake (Follenius et al., 1982). According to a study from 1981 the most important stimulus for postprandial increased cortisol are proteins (Slag et al., 1981), while other studies showed similar effect of carbohydrates and lipids (Benedict et al., 2005; Stimson et al., 2014). A varied diet 


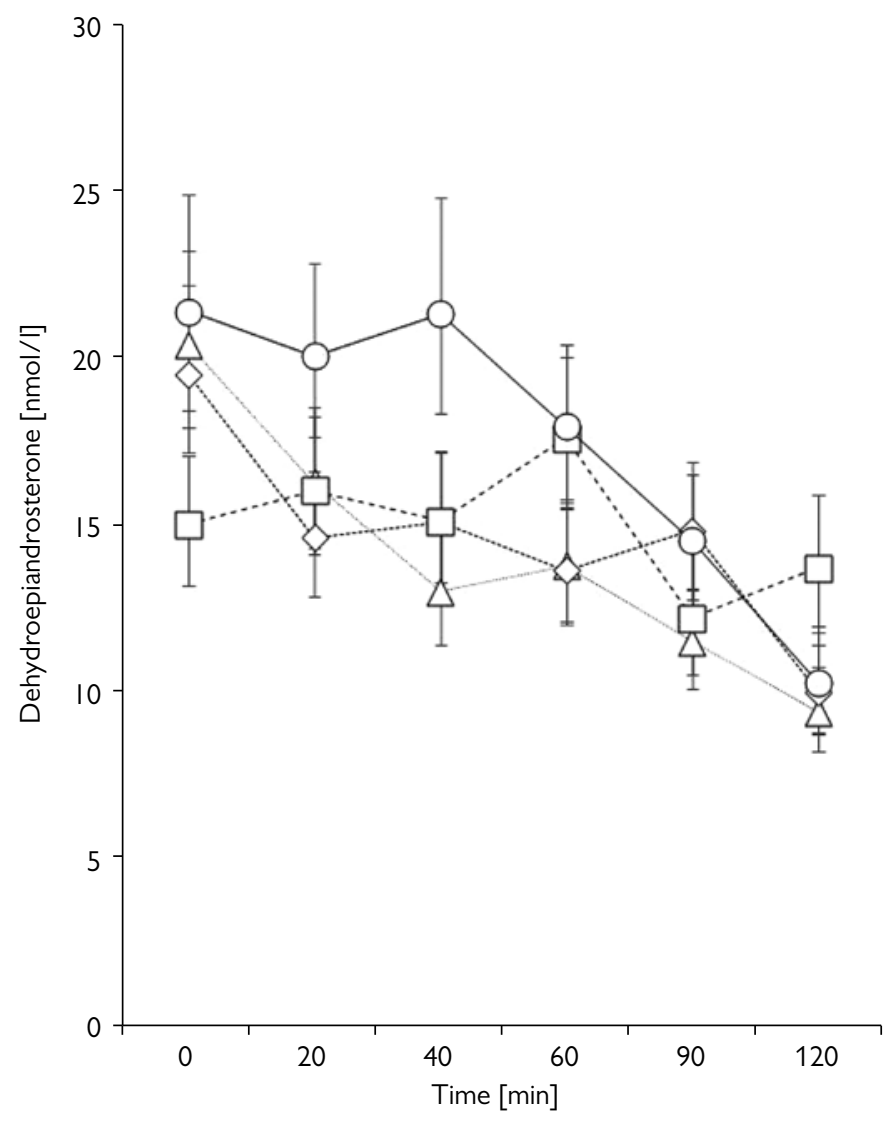

Figure 5 - DHEA levels after individual stimuli.

$\Delta$ - standard breakfast; $\square$ - IVGTT; $\diamond-O G T T ; \bigcirc-$ psyllium

and infusion of glucose and insulin (Wake et al., 2006) lead to changes of cortisone to active cortisol by activation of the enzyme 11 $\beta$-hydroxysteroid-dehydrogenase 1 (Basu et al., 2004). According to Stimson et al. (2014), postprandial increase of cortisol is influenced not only by the increased production of cortisol from cortisone, but also by its increased secretion from the adrenal. In our study we found a delay in the physiological decline in cortisol levels connected to some of the stimuli. This delay was most pronounced after intravenous glucose admission and lasted until the $60^{\text {th }}$ minute. After the breakfast there was an increase in cortisol levels at $40^{\text {th }}$ minute, in accordance with the results of other studies.

The parenteral versus oral application of the studied stimuli can also play an important role. The postprandial increase of cortisol after oral nutritional stimulus is assumed to be influenced by signalling from the gastrointestinal tract (likely incretins, glucagon-like peptide 1 , and gastric inhibitory polypeptide, which stimulate the hypothalamic-pituitary-adrenal axis (Herrmann et al., 1995). It is 


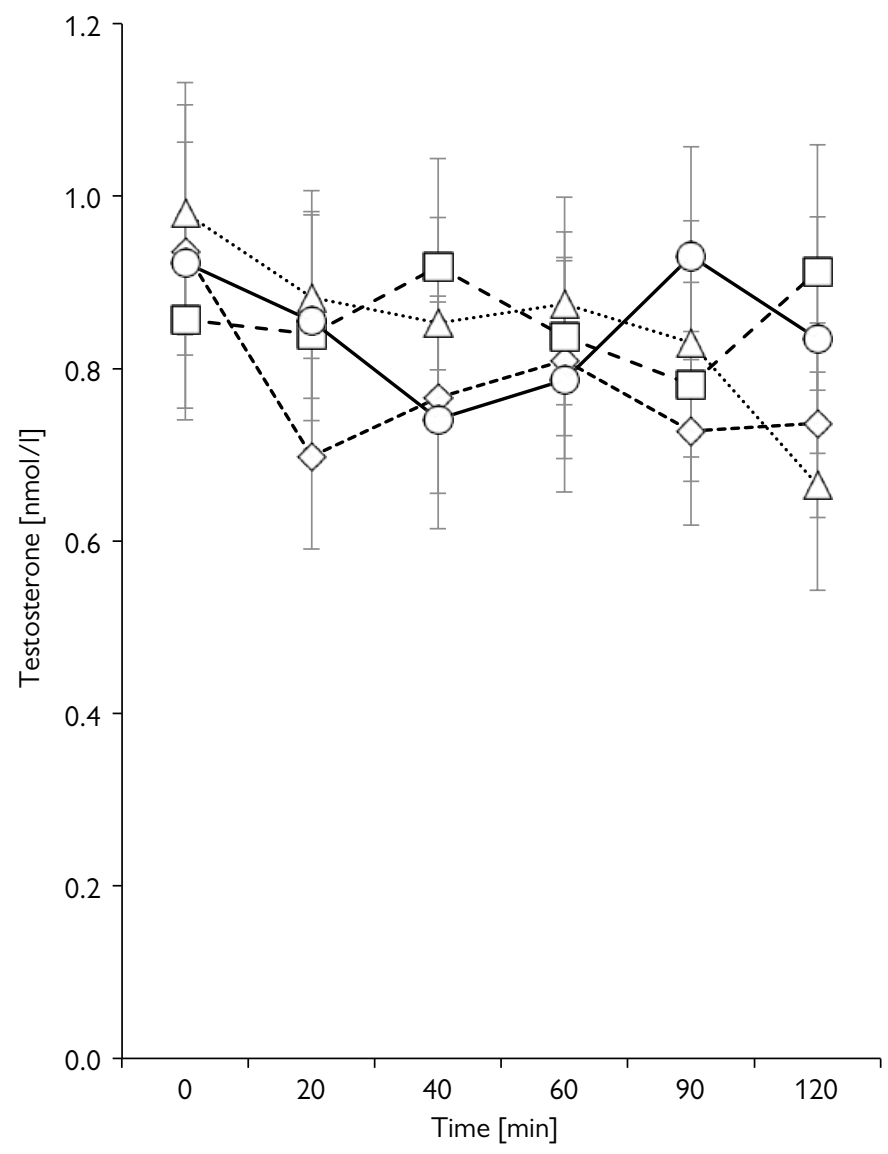

Figure 6 - Testosterone levels after individual stimuli.

$\Delta$ - standard breakfast; $\square$ - IVGTT; $\diamond-O G T T ; \circ-$ psyllium

further known that OGTT leads to a "blunting" in the character of cortisol decline (Reynolds et al., 2001). This could be explained by the plateau we found in cortisol levels. We found only one paper in the literature showing that psyllium influences corticoid supplies, describing adrenal crisis in a patient treated with prednisone and concurrently given psyllium (Ahi et al., 2011). Oltmanns et al. (2006) studied patients with diabetes mellitus type 2 during 24 hours. They found, that higher cortisol levels where associated with not only higher fasting glucose and glycosuria, but with higher postprandial glycemia, glycosylated hemoglobin, systolic and diastolic blood pressures too. In addition they found (except the morning physiological cortisol surge half hour after arising) an another cortisol peak one hour after the lunch, but after dividing the subject in tertiles they have found, that actually the after-lunch peak of cortisol wasn't present in case of highcortisol group, in contrast to the other two tertiles. Due to the low number 
of participants in our study, we were not able to divide them according to the cortisol levels. But it would be interesting to analyse these founding on nondiabetic subjects.

Giving DHEA for long-term (for 2 years) at a dose of $50 \mathrm{mg} /$ day led to improved glucose tolerance and insulin sensitivity in patients with impaired glucose tolerance (both men and women), and further led to decrease of plasma triglycerides (Weiss et al., 2011). It is also known that moderated alcohol consumption can lead to increased plasmatic DHEAS (Sierksma et al., 2004). However, studies are lacking that would show the effects of food/glucose on DHEA levels. Our results indicate a certain increase of DHEA levels after all stimuli after the initial decline at the beginning of the tests. This increase was most pronounced after intravenous glucose admission, even though the increased levels were delayed compared to the other stimuli despite the fact that the opposite effect might be expected, thanks to the immediate increase of glucose levels after its intravenous application and the highest glycemia obtained from all of the tests.

Our data on the behaviour of melatonin after individual stimuli resulted in interesting findings, which should help to elucidate, for instance, the possibility to influence levels of this hormone through only natural dietary changes. This is important, since melatonin is a hormone of which there is recently much interest and which potentially has a wide spectrum of use. It would be certainly interesting if by intentional control of what we eat or drink, we could influence plasmatic levels of hormones, and in this way obtain their benefits for our health without the need of synthetic hormones or dietary supplements.

\section{Conclusion}

By the application of various stimuli we attempted to simulate different situations in the organism, including stimulation through the gastrointestinal (Gl) tract as well as bypassing the Gl tract by giving glucose intravenously, and by avoiding the caloric effect of food but using mechanical distension of the Gl tract through non-caloric fibre. We followed changes in the levels of melatonin and steroid hormones. Melatonin levels physiologically decreased in the morning and a certain increase in levels were found after intravenous glucose (from $20^{\text {th }}$ to $60^{\text {th }}$ minute) and after oral glucose at $60^{\text {th }}$ minute of the tests. The other stimuli did not lead to increased levels. There was a delay in the physiological decline of the cortisol after each individual stimulus (except psyllium), but which was most pronounced after intravenous glucose admission. After the standard breakfast there was an increase in the cortisol level at $40^{\text {th }}$ minute. DHEA levels declined at the beginning of the tests, but then it was followed by a certain increase. One of the weaknesses of our study was the timing of the samplings in the early morning hours, when there are large physiological changes in hormones that might mask small changes induced by the intake of various foods. It would be likely better to perform the study in the later afternoon hours. Another weakness was not including starvation 
as a reference profile, even if we used a non-caloric stimulation represented by psyllium. Despite these weaknesses, our results have brought interesting findings.

\section{References}

Ahi, S., Esmaeilzadeh, M., Kayvanpour, E., Sedaghat-Hamedani, F., Samadanifard, S. H. (2011) A bulking agent may lead to adrenal insufficiency crisis: a case report. Acta Med. Iran. 49(10), 688-689.

Basu, R., Singh, R. J., Basu, A., Chittilapilly, E. G., Johnson, C. M., Toffolo, G., Cobelli, C., Rizza, R. A. (2004) Splanchnic cortisol production occurs in humans: Evidence for conversion of cortisone to cortisol via the 11-beta hydroxysteroid dehydrogenase (11beta-hsd) type 1 pathway. Diabetes 53(8), 2051-2059.

Benedict, C., Hallschmid, M., Scheibner, J., Niemeyer, D., Schultes, B., Merl, V., Fehm, H. L., Born, J., Kern, W. (2005) Gut protein uptake and mechanisms of meal-induced cortisol release.J. Clin. Endocrinol. Metab. 90(3), 1692-1696.

Follenius, M., Brandenberger, G., Hietter, B. (1982) Diurnal cortisol peaks and their relationships to meals. J. Clin. Endocrinol. Metab. 55(4), 757-761.

Herrmann, C., Göke, R., Richter, G., Fehmann, H. C., Arnold, R., Göke, B. (1995) Glucagon-like peptide-1 and glucose-dependent insulin-releasing polypeptide plasma levels in response to nutrients. Digestion 56(2), 117-126.

Hill, M., Pařízek, A., Kancheva, R., Dušková, M., Velíková, M., Kř̌̌ž, L., Klímková, M., Pašková, A., Žižka, Z., Matucha, P., Meloun, M., Stárka, L. (2010) Steroid metabolome in plasma from the umbilical artery, umbilical vein, maternal cubital vein and in amniotic fluid in normal and preterm labor. J. Steroid Biochem. Mol. Biol. 121, 594-610.

Lecocq, F. R., Mebane, D., Madson, L. L. (1964) The acute effect of hydrocortisone on hepatic glucose output and peripheral glucose utilization. J. Clin. Invest. 43, 237-246.

Lightman, S. L., Wiles, C. C., Atkinson, H. C., Henley, D. E., Russell, G. M., Leendertz, J. A., McKenna, M. A., Spiga, F., Wood, S. A., Conway-Campbell, B. L. (2008) The significance of glucocorticoid pulsatility. Eur. J. Pharmacol. 583(2-3), 255-262.

Meloun, M., Hill, M., Militký, J., Kupka, A. K. (2000) Transformation in the PC-aided biochemical data analysis. Clin. Chem. Lab. Med. 38, 553-559.

Meloun, M., Militký, J., Hill, M., Brereton, R. G. (2002) Crucial problems in regression modelling and their solutions. Analyst 127, 433-450.

Meloun, M., Hill, M., Militký, J., Vrbíková, J., Stanická, S., Škrha, J. (2004) New methodology of influential point detection in regression model building for the prediction of metabolic clearance rate of glucose. Clin. Chem. Lab. Med. 42, 311-322.

Oltmanns, K. M., Dodt, B., Schultes, B., Raspe, H. H., Schweiger, U., Born, J., Fehm, H. L., Peters, A. (2006) Cortisol correlates with metabolic disturbances in a population study of type 2 diabetic patients. Eur. J. Endocrinol. 154(2), 325-331.

Peuhkuri, K., Sihvola, N., Korpela, R. (2012) Dietary factors and fluctuating levels of melatonin. Food Nutr. Res. 56, 1-9.

Rácz, B., Dušková, M., Vondra, K., Šrámková, M., Stárka, L. (2015) Daily profiles of steroid hormones and their metabolites related to food intake. Physiol. Res. 64, (Suppl. 2). (in press)

Reynolds, R. M., Walker, B. R., Syddall, H. E., Whorwood, C. B., Wood, P. J., Phillips, D. I. (2001) Elevated plasma cortisol in glucose-intolerant men: differences in responses to glucose and habituation to venepuncture. J. Clin. Endocrinol. Metab. 86(3), 1149-1153.

Röjdmark, S., Wetterberg, L. (1989) Short-term fasting inhibits the nocturnal melatonin secretion in healthy man. Clin. Endocrinol. (Oxf.) 30(4), 451-457. 
Sherman, H., Gutman, R., Chapnik, N., Meylan, J., le Coutre, J., Froy, O. (2011) Caffeine alters circadian rhythms and expression of disease and metabolic markers. Int. J. Biochem. Cell Biol. 43(5), 829-838.

Sierksma, A., Sarkola, T., Eriksson, C. J., van der Gaag, M. S., Grobbee, D. E., Hendriks, H. F. (2004) Effect of moderate alcohol consumption on plasma dehydroepiandrosterone sulfate, testosterone, and estradiol levels in middle-aged men and postmenopausal women: a diet-controlled intervention study. Alcohol Clin. Exp. Res. 28(5), 780-785.

Slag, M. F., Ahmad, M., Gannon, M. C., Nuttall, F. Q. (1981) Meal stimulation of cortisol secretion: a protein induced effect. Metabolism 30(11), 1104-1108.

Spanagel, R., Rosenwasser, A. M., Schumann, G., Sarkar, D. K. (2005) Alcohol consumption and the body's biological clock. Alcohol Clin. Exp. Res. 29(8), 1550-1557.

Stárka, L., Rácz, B., Šrámková, M., Hill, M., Dušková, M. (2015) Daily profiles of dehydroepiandrosterone and its hydroxylated metabolites with respect to food intake. Prague Med. Rep. 116(1), 40-48.

Stimson, R. H., Mohd-Shukri, N. A., Bolton, J. L., Andrew, R., Reynolds, R. M., Walker, B. R. (2014) The postprandial rise in plasma cortisol in men is mediated by macronutrient-specific stimulation of adrenal and extra-adrenal cortisol production. J. Clin. Endocrinol. Metab. 99(1), 160-168.

Wake, D. J., Homer, N. Z., Andrew, R., Walker, B. R. (2006) Acute in vivo regulation of 11 beta-hydroxysteroid dehydrogenase type 1 activity by insulin and intralipid infusions in humans. J. Clin. Endocrinol. Metab. 91(11), 4682-4688.

Weiss, E. P., Villareal, D. T., Fontana, L., Han, D. H., Holloszy, J. O. (2011) Dehydroepiandrosterone (DHEA) replacement decreases insulin resistance and lowers inflammatory cytokines in aging humans. Aging (Albany NY) 3(5), 533-542. 